УДК 159.91

\title{
ПСИХОСОМАТИЧЕСКАЯ ХАРАКТЕРИСТИКА ЖЕНЩИН РЕПРОДУКТИВНОГО ВОЗРАСТА, БОЛЬНЫХ ТУБЕРКУЛЕЗОМ ОРГАНОВ ДЫХАНИЯ
}

\author{
Русановская Галина Федоровна \\ Камаев Игорь Александрович \\ Шпрыков Александр Сергеевич
}

Проведена оченка психосоматического статуса среди 175 женщин репродуктивного возраста. Основную группу составили 93 женшины в возрасте 18-44 года, больные активным туберкулезом органов дыхания, получавшие лечение в одном из противотуберкулезных учреждений Нижегородской области в 2013 г.; группу сравнения составили 82 практически здоровые женщины соответствующего возраста. Для оценки психоэмоционального состояния проводилось тестирование по методике теста «САН» (самочувствие, активность, настроение), для оценки личностных особенностей - тестирование по методике «Самооценка личности» (О. И. Мотков), для оченки межличностных отношений - тестирование по методике теста Лири.

Доказано, что заболевание туберкулезом органов дыхания данной категории пациенток оказывает значительное негативное влияние на их психоэмоциональное состояние, вызывая неудовлетворительное самочувствие (оценено наиболее низко), низкую активность, плохое настроение. В процессе длительного лечения у женщин нарастает усталость. Общая самооценка личности исследуемой группы женщин находится на среднем уровне, что свидетельствует о ее адекватности, но значение показателя является пограничным с низким уровнем самооценки.

Личностными особенностями женщин являются наличие непокладистого, неуравновешенного, негармоничного характера с отсутствием чувства меры в желаниях и поведении. Наименее им присущи - доброжелательность, искренность, правдивость, отзывчивость, самостоятельность, общительность, оптимизм, уверенность, жизнестойкость, креативность (оценена наиболее низко). Поведение женщин является адаптивным, что свидетельствует о гармоничности их личности. Основными типами межличностных отношений женщин, больных туберкулезом, являются, с одной стороны, «дружелюбный» и «альтруистический», с другой стороны - «зависимый». Поэтому необходимо разрабатывать мероприятия по организации психологической помощи больным активным туберкулезом органов дыхания женщинам репродуктивного возраста и новые подходы в профилактике 
этого заболевания с опорой на установленные психологические факторы риска возникновения туберкулезного процесса и его рецидивов.

Ключевые слова: туберкулез, органы дыхания, женшины, репродуктивный возраст, психосоматическая характеристика, психологическая помощь.

\section{Введение}

Психосоматика - медико-психологическое направление, изучающее влияние психологических факторов на возникновение и течение соматических заболеваний. Соматопсихическое направление в отечественной медицине было заложено трудами С. С. Корсакова, П. Б. Ганнушкина, В. А. Гиляревского, И. К. Краснушкина, М. Я. Мудрова, Р. А. Лурия [9, 10]. К сожалению, следует признать, что психосоматика, достаточно разработанная на теоретическом уровне, пока не приобрела популярности в отечественном здравоохранении и медленно внедряется в медицинскую практику.

Использование психосоматических характеристик пациентов при различных, в том числе инфекционных, заболеваниях позволяет глубоко осмыслить как причины патологических процессов, так и пути их «преодоления». Сегодня такой подход становится особо востребованным в лечении туберкулеза болезни, давно именуемой социальной [8, с. 25-32; 13, с. 47-51].

Заболевание туберкулезом органов дыхания у женщин фертильного возраста (18-44 лет) выступает как психотравмирующий фактор и обусловливает специфические эмоциональные реакции, поведение, и способствует изменению мировоззрения и отношения к действительности. Госпитализация, необходимость длительного лечения, страх за свое здоровье и здоровье близких (детей, супруга, родителей, родственников, знакомых, коллег и т. д.) в связи с наличием контакта переживаются как тяжелый стресс, связанный с резким изменением привычного стиля жизни, социального статуса, ограничениями семейного и межличностного общения, зависимостью от медицинского персонала, и сопровождаются стойкими негативными эмоциональными реакциями $[11$, с. $71-72 ; 12$, с. 88-89; 14, с. 31-37; 15, с. 22-37; 19, с. 375-380; 20, с. 620-654; 21, с. 830-837; 22, с. 51-79]. Понимание условий формирования специфических особенностей черт личности, психоэмоционального состояния и системы взаимоотношений с окружением данной категории пациентов позволят адекватно оценить сущность нарушений их адаптации в социальной среде [16, с. 34-36; 18, с. 20-23]. Решение поставленных исследовательских задач возможно при применении адекватного набора психологических методик [1, с. 6-10; 3, с. 3-6; 4, с. 56-60; 5, с. 30-34; 6, с. 16-19; 7, с. 38-40; 17, с. 47-50].

Цель исследования: изучить особенности психосоматического статуса женщин репродуктивного возраста, больных туберкулезом органов дыхания. 


\section{Материалы и методы}

Проведено комплексное медико-психологическое исследование по определению особенностей психосоматического статуса женщин репродуктивного возраста, больных активным туберкулезом органов дыхания.

Сбор данных осуществлялся путем тестирования с соблюдением принципов добровольности и анонимности. Респондентам разъясняли цели проведения тестирования и правила заполнения опросника, после чего тестируемый самостоятельно заполнял опросник.

Объектом исследования явились 93 женщины в возрасте 18-44 лет, больные активным туберкулезом органов дыхания, получавшие противотуберкулезную химиотерапию в одном из противотуберкулезных учреждений Нижегородской области в 2013 г.; группу сравнения составили 82 практически здоровые женщины соответствующего возраста.

Для определения психоэмоционального состояния вышеуказанного контингента была использована методика тестирования «САН» (самочувствие, активность, настроение), направленная на дифференциальную самооценку пациентками своего функционального состояния.

Личностные особенности больных с данной нозологией были выявлены с использованием методики «Самооценка личности» (О. И. Мотков), которая позволила изучить общий уровень самооценки позитивного развития личности, отдельных ее факторов и качеств, а также степень ее адекватности. Псевдовысоким уровнем выраженности самооценки являлся диапазон от 4,51-4,71 балла до максимальной границы 5,00 баллов, низким - диапазон $1,00-2,90$.

Для определения характерных особенностей межличностного взаимодействия больных туберкулезом органов дыхания женщин репродуктивного возраста с их социальным окружением (супругом, родителями, соседями, коллегами по работе и т. д.), а также характерных стратегий поведения в конфликте была использована методика теста Лири. Электронная база данных исследования была создана с помощью СУБД Microsoft Office Excel 2007. Статистическая обработка осуществлялась с помощью специализированного пакета прикладных программ SPSS 17.0. Для описательной статистики рассчитывались средние значения (М) и относительные показатели (Р, в \%) в виде $\mathrm{M} \pm \mathrm{m}$ и $\mathrm{P} \pm \mathrm{m}$, где $\mathrm{m}$ - ошибка средней величины или относительного показателя. Также использовались критерий хи-квадрат Пирсона или точный тест Фишера, U-тест Манна-Уитни, критерий Краскела-Уоллиса, критерий корреляции R Спирмена [2]. Критический порог статистической значимости определили на уровне $p<0,05$.

Обе сравниваемые группы больных туберкулезом органов дыхания и здоровых лиц были одинаковы по возрастному составу. Средний возраст 


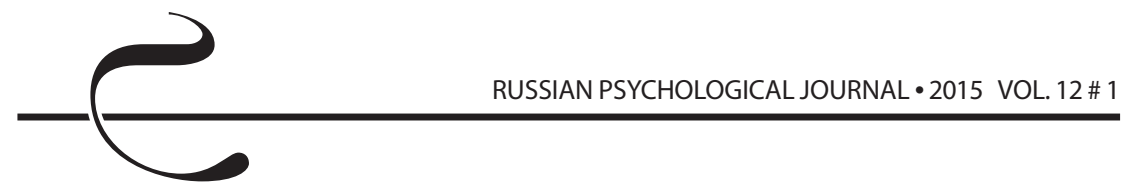

в основной группе составил $30,3 \pm 0,6$ лет, в группе сравнения - $30,8 \pm 0,4$ лет ( $p=0,656$ по тесту Манна-Уитни).

Впервые выявленный туберкулезный процесс был зарегистрирован у $68,8 \pm 2,8 \%$ женщин основной группы, рецидив заболевания $-6,4 \pm 5,1 \%$, туберкулез хронического течения - 24,7 $\pm 4,2 \%$.

В анализируемой группе наиболее часто регистрировалась инфильтративная форма туберкулеза (49,4 \pm 4,6 \%), «малые» формы туберкулеза (очаговая, туберкулезный плеврит, туберкулома) - 34,4 \pm 1,2 \% случаев, распространенные формы туберкулеза (диссеминированная, фибрознокавернозная) - в 16,1 $\pm 3,4 \%$ случаев.

Несмотря на относительно благоприятную клиническую структуру, у 51,6 $\pm 1,9 \%$ больных было обнаружено бактериовыделение, у $67,7 \pm 4,7 \%$ деструктивные изменения в легочной ткани. В представленной группе женщин репродуктивного возраста, больных туберкулезом органов дыхания, $62,3 \%$ получали только стационарное лечение, 32,3 \% - только амбулаторное, $5,4 \%$ - амбулаторное и стационарное.

\section{Результаты и обсуждение}

Результаты тестирования по определению психосоматического статуса, проведенного женщинам репродуктивного возраста, больным активным туберкулезом органов дыхания, показали следующее.

Параметры психоэмоционального состояния, факторы (аспекты) личности и показатели личностного профиля анализируемой группы больных были сопоставимы с аналогичными параметрами здоровых лиц контрольной группы.

Все параметры психоэмоционального состояния анализируемой группы больных были значительно снижены. Данные представлены в таблице 1.

Таблица 1.

Показатели психоэмоционального состояния женщин репродуктивного возраста, больных туберкулезом органов дыхания, и здоровых женщин (на основании теста САН - самочувствие, активность, настроение), баллы (M $\pm \mathrm{m}$ )

\begin{tabular}{|l|c|c|c|}
\hline \multicolumn{1}{|c|}{ Шкала } & $\begin{array}{c}\text { осн. 2p. } \\
\boldsymbol{n = 9 3}\end{array}$ & $\begin{array}{c}\text { контр. 2p. } \\
\boldsymbol{n = 8 2}\end{array}$ & $\boldsymbol{p}$ \\
\hline Самочувствие & $3,67 \pm 0,05$ & $5,71 \pm 0,06$ & $<0,0001^{*}$ \\
\hline Активность & $3,73 \pm 0,05$ & $5,52 \pm 0,05$ & $<0,0001^{*} 6$ \\
\hline Настроение & $3,82 \pm 0,06$ & $5,76 \pm 0,06$ & $<0,0001^{* 6}$ \\
\hline $\begin{array}{l}\text { Интегральный показатель психо- } \\
\text { эмоционального состояния }\end{array}$ & $3,74 \pm 0,03$ & $5,66 \pm 0,04$ & $<0,0001^{*}$ \\
\hline
\end{tabular}

Примечание: * - различия статистически значимы $(\mathrm{p}<0,05)$. 
Так, оценка самочувствия в основной группе на 54,1 \% ниже, чем в группе сравнения ( $p<0,001)$, и свидетельствует о том, что у женщин, больных туберкулезом органов дыхания, работоспособность и выносливость ограничены состоянием здоровья; активность - на 48,6 \% ниже, чем в группе сравнения ( $>$ < 0,001), и свидетельствует о том, что подвижность, деятельность, увлеченность, внимательность, желание работать в основной группе женщин значительно ограничены физическим состоянием здоровья, обусловленным основным заболеванием; настроение - на 52,6 \% ниже, чем в группе сравнения ( $p=0,001)$, и свидетельствует о том, что жизнерадостность, спокойствие, оптимистичность у женщин, больных туберкулезом органов дыхания, снижены.

Интегральный показатель психоэмоционального состояния женщин основной группы на 54,1 \% ниже, чем в группе сравнения, что свидетельствует о неудовлетворительном самочувствии, низкой активности и плохом настроении, обусловленными заболеванием туберкулезом органов дыхания.

При сравнении значений шкал между собой в основной группе наиболее низко оценено самочувствие (3,67 балла), в группе сравнения - активность (5,52 балла). Кроме этого, следует отметить, что у женщин репродуктивного возраста, больных туберкулезом органов дыхания, в процессе динамического наблюдения и проведения длительной противотуберкулезной химиотерапии нарастает усталость, о чем свидетельствуют наиболее низкие показатели самочувствия и активности по сравнению с настроением.

Факторы (аспекты) личности основной группы женщин были снижены умеренно (таблица 2).

\section{Таблича 2.}

Оценка личностных особенностей женщин репродуктивного возраста, больных туберкулезом органов дыхания, и здоровых женщин (на основании методики «Самооценка личности» по О. И. Моткову), баллы (M $\pm \mathrm{m})$

\begin{tabular}{|l|c|c|c|}
\hline \multicolumn{1}{|c|}{$\begin{array}{c}\text { Факторы (аспекты) } \\
\text { личности }\end{array}$} & $\begin{array}{c}\text { осн. 2p. } \\
\boldsymbol{n = 9 3}\end{array}$ & $\begin{array}{c}\text { контр. 2p. } \\
\boldsymbol{n = 8 2}\end{array}$ & $\boldsymbol{p}$ \\
\hline Нравственность & $3,38 \pm 0,05$ & $3,84 \pm 0,05$ & $<0,0001^{*}$ \\
\hline Воля & $2,96 \pm 0,05$ & $3,41 \pm 0,05$ & $<0,0001^{*}$ \\
\hline Самостоятельность и чувство реальности & $3,04 \pm 0,05$ & $3,64 \pm 0,05$ & $<0,0001^{*}$ \\
\hline Креативность & $2,87 \pm 0,05$ & $3,32 \pm 0,05$ & $<0,0001^{*}$ \\
\hline Гармоничность & $2,95 \pm 0,05$ & $3,37 \pm 0,05$ & $<0,00016$ \\
\hline Экстраверсия & $2,95 \pm 0,05$ & $3,52 \pm 0,05$ & $<0,0001^{*}$ \\
\hline $\begin{array}{l}\text { Общая самооценка позитивных аспектов } \\
\text { личности (интегральный показатель лич- } \\
\text { ностных особенностей) }\end{array}$ & $3,01 \pm 0,02$ & $3,50 \pm 0,02$ & $<0,0001^{*}$ \\
\hline
\end{tabular}

Примечание: * - различия статистически значимы $(p<0,05)$. 
Так, оценка нравственности у женщин, больных туберкулезом органов дыхания, на 12,9 \% ниже, чем у здоровых женщин ( $<<0,001)$, что свидетельствует о том, что для женщин основной группы воспитанность (уважение к людям), доброжелательность, искренность, правдивость, отзывчивость (сочувствие, помощь другому) характерны в меньшей степени; воля - на 13,7 \% ниже, чем в группе сравнения ( $<<0,001)$, что свидетельствует о том, что жизнестойкость, настойчивость, сдержанность, собранность (неотвлекаемость) присущи им в меньшей степени; самостоятельность - на 21,3 \% ниже, чем у здоровых женщин ( $p<0,001)$, что указывает на более низкий уровень разумности (учета реальной ситуации), самокритичности (способности видеть у себя и плюсы, и минусы), самостоятельности (чаще - опора на себя), независимости суждений у женщин, больных туберкулезом; креативность - на 14,5 \% ниже, чем в группе здоровых женщин ( $p<0,001)$, что указывает на более низкую выраженность инициативности (выдвижения идей), увлеченности чем-то интересным, чувства красоты, творческости (оригинальности) в группе больных туберкулезом органов дыхания женщин; гармоничность - на $12,3$ \% ниже, чем у здоровых женщин ( $<<0,001)$, что указывает на преобладание в основной группе женщин репродуктивного возраста непокладистого, неуравновешенного, негармоничного характера с отсутствием чувства меры в желаниях, поведении; экстраверсия - на 17,3 \% ниже, чем в основной группе ( $<<0,001)$, что указывает на более низкую выраженность активности, общительности, оптимизма, жизнерадостности (веры в лучшее), уверенности в основной группе женщин.

При сравнении значений факторов между собой в обеих группах наиболее низко оценена креативность (2,87 балла - в основной группе; 3,32 балла - в группе сравнения), наиболее высоко оценена в обеих группах нравственность (3,38 и 3,84 балла соответственно).

Уровни выраженности интегрального показателя общей самооценки позитивных аспектов личности в обеих группах находились на среднем уровне, что свидетельствует об адекватности самооценки анкетируемых, но следует отметить, что в группе женщин репродуктивного возраста, больных туберкулезом органов дыхания, значения показателя соответствуют нижней границе среднего уровня (3,0 балла) и являются пограничными с низким уровнем самооценки.

Показатели личностного профиля женщин основной группы также были снижены умеренно (рисунок 1). В обеих исследуемых группах женщин получены характеристики, не выходящие за пределы 8,0 баллов, что свидетельствует об их адаптивном поведении и гармоничности личности. 


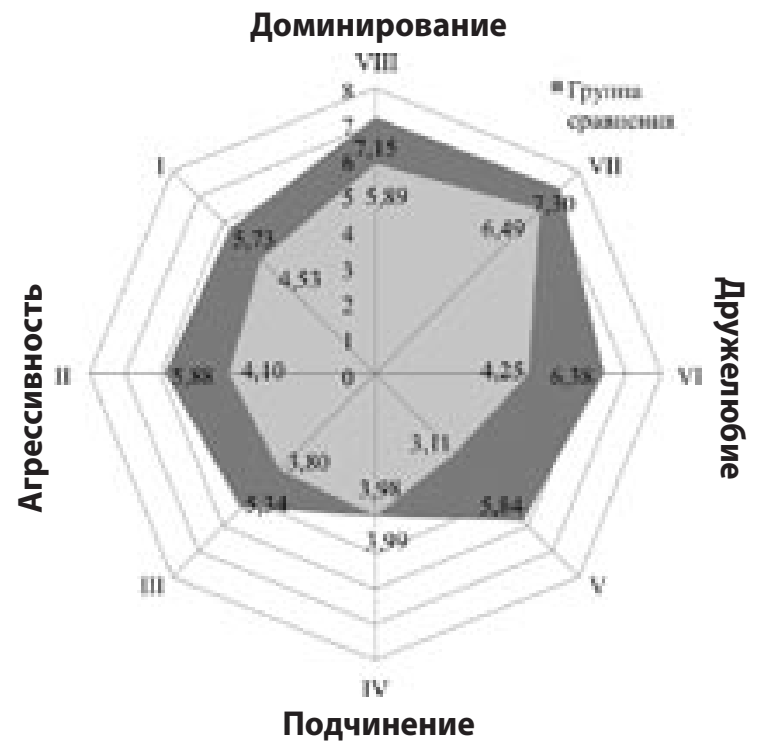

Рисунок 1. Психограмма женщин репродуктивного возраста, баллы

I (Авторитарный)
II (Эгоистичный)
III (Агрессивный)
IV (Подозрительный)
V (Подчиняемый)
VI (Зависимый)
VII (Дружелюбный)
VIII (Альтруистический)

Основная группа

4,53

4,10

3,80

3,98

3,11

4,25

6,49

5,89
Группа сравнения

5,73

5,88

5,34

3,99

5,84

6,38

7,30

7,15

Параметр «дружелюбие» оценен наиболее высоко в обеих анализируемых группах женщин, и получены положительные значения результатов (основная группа - 4,14 балла, группа сравнения - 4,52 балла), что является показателем стремления личности женщин к установлению дружелюбных отношений и сотрудничеству с окружающими людьми. Наиболее низко оценен в обеих группах женщин параметр «доминирование», получены положительные его значения (основная группа - 2,65 балла, группа сравнения - 1,75 балла), что свидетельствует о выраженном стремлении женщин к лидерству в общении, к доминированию. Следует отметить, что в группе женщин, больных туберкулезом органов дыхания, количественное 
значение показателя выше, чем у здоровых женщин, что свидетельствует о большей степени выраженности этой характеристики.

В обеих исследуемых группах преобладают VII (основная группа - 6,49 балла, группа сравнения - 7,30 балла $(p=0,048)$ ), VIII (основная группа - 5,89 балла, группа сравнения - 7,15 балла $(p=0,012)$ ), VI (основная группа - 4,25 балла, группа сравнения - 6,38 балла $(p<0,0001)$ ) октанты, которые отражают преобладание комфортных установок межличностного взаимодействия, конгруэнтность в контактах с окружающими людьми (VII, VIII октанты), неуверенность в себе, податливость мнению окружающих, склонность к компромиссам (VI октант), но количественные их результаты свидетельствуют о меньшей степени их выраженности в основной группе женщин.

В группе женщин, больных туберкулезом, наиболее низко оценен V октант $(3,11$ балла ( $<<0,0001))$, что свидетельствует о неудовлетворенности собой и заниженной самооценке. В группе здоровых женщин наиболее низко оценен IV октант $(3,99$ балла ( $=0,985))$, который характеризует женщин, находящихся в ситуации затянувшегося конфликта.

Преобладающими типами межличностных отношений в обеих группах женщин являются «дружелюбный» (основная группа - 6,49 балла, группа сравнения - 7,30 балла $(p=0,048)$ ), характеризующий человека упорного, настойчивого, но не обязательно лидера; «альтруистический» (основная группа - 5,89 балла, группа сравнения - 7,15 балла $(p=0,012)$ ), характеризующий человека, ответственного по отношению к другим людям, деликатного, мягкого, доброго, бескорыстного, отзывчивого, проявляющего эмоциональное отношение к людям в сострадании, симпатии, заботе, ласке, умеющего подбодрить и успокоить окружающих; «зависимый» (основная группа - 4,25 балла, группа сравнения - 6,38 балла ( $(<0,0001))$, характеризующий комфортного, вежливого, мягкого, доверчивого человека, ожидающего помощи и советов, склонного к восхищению окружающими людьми. Следует отметить, что количественные результаты типов межличностного взаимодействия у женщин основной группы ниже, чем в группе сравнения, что свидетельствует о меньшей степени их выраженности.

Таким образом, определяющими направлениями, по которым самостоятельно движется личность женщин репродуктивного возраста, больных туберкулезом органов дыхания, в целях самосовершенствования, учитывая степень осознания имеющихся проблем, наличия внутриличностных ресурсов, являются: стремление к сотрудничеству с группой людей, дружелюбие, готовность помогать и сочувствовать окружающим, потребность в помощи и доверии со стороны близкого окружения. 


\section{Заключение}

На основании анализа результатов тестирования, проведенного женщинам репродуктивного возраста, больным активным туберкулезом органов дыхания, выявлены следующие особенности их психосоматического статуса:

1. Заболевание туберкулезом органов дыхания данной категории пациенток оказывает значительное негативное влияние на их психоэмоциональное состояние, вызывая неудовлетворительное самочувствие, низкую активность, плохое настроение. Наибольшее негативное влияние туберкулез оказывает на самочувствие. В процессе длительного лечения у женщин нарастает усталость.

2. Общая самооценка личности исследуемой группы женщин находится на среднем уровне, что свидетельствует о ее адекватности, но значение показателя является пограничным с низким уровнем самооценки. Личностными особенностями женщин являлись наличие непокладистого, неуравновешенного, негармоничного характера с отсутствием чувства меры в желаниях и поведении. Наименее им присущи - доброжелательность, искренность, правдивость, отзывчивость, самостоятельность, общительность, оптимизм, уверенность, жизнестойкость, креативность (оценена наиболее низко).

3. Основными социальными ориентациями личности женщин, больных туберкулезом органов дыхания, являются, с одной стороны, дружелюбные и альтруистические отношения с окружающими людьми, с другой стороны неуверенность и неудовлетворенность собой, заниженная самооценка, податливость к мнению окружающих, ожидание их помощи и советов.

Таким образом, результаты проведенного тестирования показали необходимость в разработке мероприятий по организации психологической помощи женщинам репродуктивного возраста, больным активным туберкулезом органов дыхания, и новых подходов в профилактике этого заболевания с опорой на установленные психологические факторы риска возникновения туберкулезного процесса и его рецидивов.

\section{Литература}

1. Алексеева Л. П., Розанова Ю. К., Петровская М. В., Мартынова М. В. Изучение нарушений личности и эмоционально-волевой сферы у лиц БОМЖ, больных туберкулезом // Туберкулез и болезни легких. - 2007. № 11. - С. 6-10.

2. Бююль А., Цёфель П. SPSS: искусство обработки информации. Platinum Edition. Пер. с нем. - СПб.: ДиаСофтЮП, 2005. - 608 с.

3. Волчегорский И. А., Новоселов П. Н., Астахова Т. В. Нарушения эмоциональной сферы у больных инфильтративным туберкулезом легких // Туберкулез и болезни легких. - 2007. - № 11. - С. 3-6. 
4. Волчегорский И. А., Новоселов П. Н., Дударова Т. П. Особенности аффективного статуса больных инфильтративным туберкулезом легких с множественной лекарственной устойчивостью M. tuberculosis // Туберкулез и болезни легких. - 2013. - № 5. - С. 56-60.

5. Зарбуев А. Н. Нервно-психическое состояние у заключенных, больных туберкулезом, в разных учреждениях пенитенциарной системы // Проблемы туберкулеза и болезней легких. - 2007. - № 12. - С. 30-34.

6. Золотова Н. В., Сиресина Н. Н., Стрельцов В. В. Исследование распространенности форм агрессии у больных впервые выявленным туберкулезом легких // Туберкулез и болезни легких. - 2007. - № 9. С. 16-19.

7. Золотова Н. В., Ахтямова А. А. Оценка личностных особенностей больных туберкулезом органов дыхания подростков с учетом рентгенологических особенностей заболевания // Туберкулез и болезни легких. - 2014. - № 8. - С. 38-40.

8. Золотова Н. В., Ахтямова А. А., Стрельцов В. В., Баранова Г. В. Психологические факторы патогенеза туберкулеза органов дыхания у детей и подростков // Туберкулез и болезни легких. - 2013. - № 4. - С. 25-32.

9. Кулаков С. А. Основы психосоматики. - СПб.: Речь, 2005. - 228 с.

10. Малкина-Пых И. Г. Психосоматика: Справочник практического психолога. - Москва: Медицина, 2005. - 101 с.

11. Мордык А. В., Подкопаева Т. Г., Герасимов П. Н., Поркулевич Н. И. Формирование подходов к созданию программ психологической реабилитации детей в очагах туберкулезной инфекции // Туберкулез и болезни легких. - 2014. - № 8. - С. 71-72.

12. Попкова Г. Г., Силантьева В. А. Арт-терапия в психологической реабилитации детей, больных туберкулезом // Туберкулез и болезни легких. 2014. - № 8. - С. 88-89.

13. Сиресина Н. Н., Стрельцов В. В., Столбун Ю. В., Сельчовский П. П. Психосоматическая характеристика больных туберкулезом легких // Туберкулез и болезни легких. - 2007. - № 10. - С. 47-51.

14. Стрельцов В. В, Баранова Г. В., Сиресина Н. Н., Столбун Ю. В., ВасильеваИ.А. Возможности оптимизации психологического состояния больных туберкулезом легких в процессе индивидуальной психологической коррекции // Туберкулез и болезни легких. - 2012. - № 3. - С. 31-37.

15. Стрельчов В. В., Золотова Н. В., Баранова Г. В., Ахтямова А. А., Харитонова Н. Ю., Васильева И.А. Особенности оказания психологической помощи больным туберкулезом легких в фазе интенсивной химиотерапии (в условиях стационара) // Туберкулез и болезни легких. - 2014. - № 2. С. 22-27. 
16. Сухова Е. В. Необходимость психологической коррекции у больных туберкулезом легких // Проблемы туберкулеза и болезней легких. 2004. - № 10. - С. 34-36.

17. Сухова Е. В. Степень удовлетворения личностных потребностей у больных туберкулезом легких // Проблемы туберкулеза и болезней легких. 2005. - № 1. - C. 47-50.

18. Сухова Е. В., Сухов В. М., Корнев А. В. Особенности отношения к болезни больных туберкулезом легких // Туберкулез и болезней легких. - 2006. № 5. - C. 20-23.

19. Janmeja A. K., Das S. K., Bhargava R., Chavan B. S. Psychotherapy improves compliance with tuberculosis treatment // Respiration. - 2005. - Vol. 72. no. 4. - pp. 375-380.

20. Paul W., Andrev S. J., Anderson T. Jr. The bright side of being blue: Depression as an adaptation for analyzing complex problems // Psychol. Rev. - 2009. Vol. 116. - no. 3. - pp. 620-654.

21. Rubin R. R., Knowler W. C., Ma Y.et. al. Depression symptoms and antidepressant medicine use in Diabetes Prevention Program partic-I pants // Diabetes Care. - 2005. - Vol. 28. - no. 4. - pp. 830-837.

22. Sweetlend A., Acha J., Guerra D. Enhancing adherence: the role of group psychotherapy in the treatment of multidrug-resistant tuberculosis in urban Peru / Cohen A., Keeinman A., Saraceno B. E., eds. The world mental health casebook: social and mental health programs in low-income countries. New York: Kluwer Academic, 2002. - pp. 51-79. 